\title{
Is It Time To Consider Global Sharing Of Integral Physics Data?
}

\section{GLOBAL 2005}

\author{
Harold F. McFarlane
}

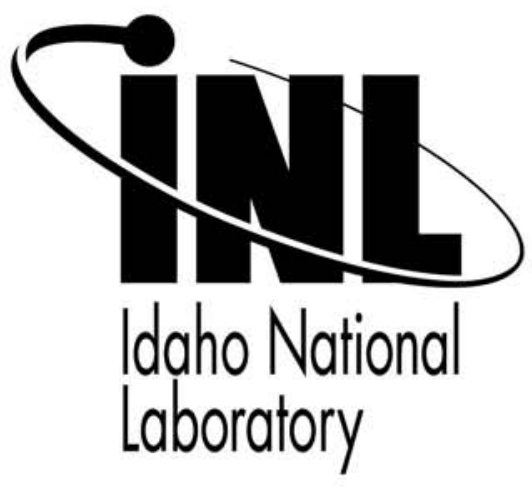

This is a preprint of a paper intended for publication in a journal or proceedings. Since changes may not be made before publication, this preprint should not be cited or reproduced without permission of the author. This document was prepared as an account of work sponsored by an agency of the United States Government. Neither the United States Government nor any agency thereof, or any of their employees, makes any warranty, expressed or implied, or assumes any legal liability or responsibility for any third party's use, or the results of such use, of any information, apparatus, product or process disclosed in this report, or represents that its use by such third party would not infringe privately owned rights. The views expressed in this paper are not necessarily those of the United States Government or the sponsoring agency. 


\title{
Is It Time to Consider Global Sharing of Integral Physics Data?
}

\author{
Harold F. MCFARLANE \\ Idaho National Laboratory, PO Box 1625-3855, Idaho Falls, ID 83415-61403855 USA \\ Tel.+1-208-526-3256, Fax.+1-208-526-2930,E-mail: harold.mcfarlane@inl.gov
}

\begin{abstract}
The innocent days of the Atoms for Peace program vanished with the suicide attack on the World Trade Center in New York City that occurred while the GLOBAL 2001 international nuclear fuel cycle conference was convened in Paris. Today's reality is that maintaining an inventory of unirradiated highly enriched uranium or plutonium for critical experiments requires a facility to accept substantial security cost and intrusion. In the context of a large collection of benchmark integral experiments collected over several decades and the ongoing rapid advances in computer modeling and simulation, there seems to be ample incentive to reduce both the number of facilities and material inventory quantities worldwide. As a result of ongoing nonproliferation initiatives, there are viable programs that will accept highly enriched uranium for down blending into commercial fuel. Nevertheless, there are formidable hurdles to overcome before national institutions will voluntarily give up existing nuclear research capabilities. GLOBAL 2005 was the appropriate forum to begin fostering a new spirit of cooperation that could lead to improved international security and better use of precious research and development resources, while ensuring access to existing and future critical experiment data.
\end{abstract}

KEYWORDS: proliferation, critical, experiment, integral, data, uranium, plutonium, sensitivity, analysis

\section{INTRODUCTION}

From the 1950's through the 1970's there were dozens of critical facilities put into operation around the world. However beginning in 1980's, the number of facilities in active use began to declined. Depending on location, materials inventory and security infrastructure, some of these facilities now represent a proliferation vulnerability.

This issue has languished as the international community has grappled with more immediate concerns. Nevertheless, this large stockpile of unirradiated highly enriched uranium and plutonium would represent a serious global threat if some of it were acquired by a terrorist network. Diversion from one country could put all countries at risk. There are only two acceptable options: continue to invest in escalating security measures or ship the inventory to a secure site.

Even though there is a cost incentive to reduce the number of critical facilities worldwide, there are also major hurdles to implementing the concept. Here we examine some of those hurdles and ways to overcome them. Because highly enriched uranium (HEU) is much more broadly distributed and represents the greater proliferation threat, we focus our remarks on the beneficial elimination of unnecessary HEU.

\section{BACKGROUND}

In order to understand the scope of the problem, it is helpful to know something about critical facilities-how they are constructed, what the materials are like, what assemblies have been tested, what the future needs are likely to be.

\section{Critical Facilities 101}

Although there are some specialty facilities with relatively fixed geometry and composition, most critical facilities are designed to be flexible enough to be able to mock up a variety of reactor designs. Materials are fabricated in the form of small plates, disks or rods, which are mixed in the optimum proportion to produce the desired composition. When all the materials are assembled in the critical array, the core is operated up to a very low power (typically less than 1000 watts), but usually in a subcritical mode ( $>95 \%$ of time). As a result, even the fuel remains relatively cold, readily handled without tools and shielding most of the time.

Because it offers the maximum flexibility, HEU has typically been the fuel of choice. By mixing HEU plates with depleted uranium plates, any core zone enrichment can be approximated. A typical loading of critical experiment materials is shown in Figure 1 for both plate and pin geometries.

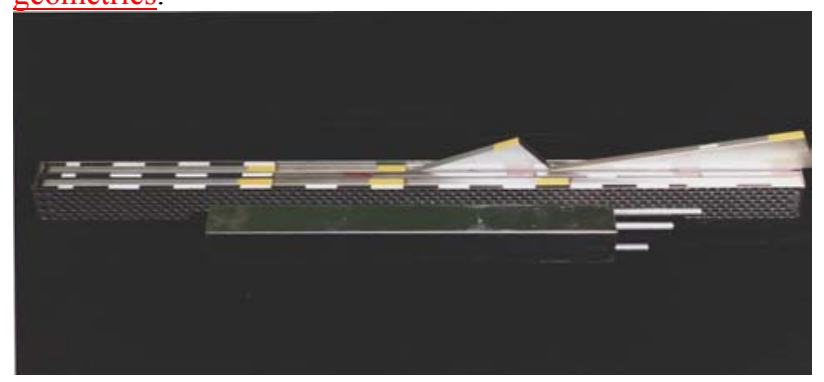

Fig. 1. Typical fast critical materials and arrangement

\section{Is HEU Really Needed?}

Historically HEU was used in some test reactors, gas-cooled reactors and some fast-spectrum reactors. With the success of the Reduced Enrichment Research and Test Reactor (RERTR) program ${ }^{2}$, new test reactor designs are using low-enriched uranium. Similarly, all proposed gas-cooled power reactor designs have been based on low-enriched uranium (LEU) for the past several years. Depending on size, 
new fast-spectrum reactor designs such as those for irradiation facilities could require HEU. Nevertheless, many of these experiments could be performed with a lower grade of HEU (e.g. $35 \%$ vs. $95 \%{ }^{235} \mathrm{U}$ ) Long-lived "nuclear battery" concepts ${ }^{3}$ such as the Toshiba 4S design have taken LEU as a design criterion. With renewed interest in large science and human exploration, the National Aeronautics and Space Administration (NASA) is expected eventually to pursue research on fission systems to provide station power and propulsion. HEU is expected to be used in these systems because of weight limitationsthe trade-off between reactor weight and cargo load.

Recently several countries with advanced nuclear energy programs have begun to discuss plans to focus research on sodium-cooled fast reactors capable of using fuel comprised of transuranics recycled from spent nuclear fuel. ${ }^{4}$ [GNEP REF-Any future critical experiments for these systems will likely require plutonium as a base fuel rather than HEU.

\section{Need for Future Critical Experiments}

With the world poised on the brink of international development of Generation-IV reactors and a new generation of space reactor designs, now is an opportune time to consider sharing historical and future integral physics data that could bear on these systems. Critical experiment data have traditionally been used to validate new reactor designs and their safety characteristics - a requirement that will not likely change for the next generation of advanced reactors.

However, data already exist from hundreds of critical assemblies covering the range of most materials of interest, notwithstanding minor actinides. Newer experiments have sometimes re-plowed old ground and have occasionally been poorly inadequately planned. New analysis tools could be developed that would eliminate the need for many future experiments as well as improve the planning for new measurements.

Critical facilities also have a role in preparing new generations of reactor physicists and criticality safety specialists. However, it seems unlikely that role requires the use of HEU.

\section{INCENTIVES FOR CONSOLIDATION}

There are multiple drivers for considering a consolidation of integral physics data programs for advanced reactor development. The underlying goals that should motivate international cooperation are cost reductions and measurable progress on global nonproliferation activities. The enabling factors in considering such a plan at this time are:

- The Generation-IV framework for international cooperation

- A wealth of excellent existing benchmark data relevant to advanced designs
- The emergence of new techniques for effectively using a broad spectrum of integral data to reduce design margins and improve confidence in safety and performance

- The rapid progress of advanced computing, modeling and simulation

- Global threat reduction initiatives to reduce inventories of highly enriched uranium (HEU) and plutonium

- The reemergence of the United States as a leader in advanced nuclear technology development

\section{More Money to Research, Less to Security}

In the United States at least, it costs far more to secure the fissile material than it does to operate a critical facility for a year, including all the measurements and analysis. Investment in physical security upgrades are costing as much as 10 times more than the original facility construction cost. Although the situation is somewhat different unique in every country, if similar-comparable security investments-upgrades are not being made for other facilities, the international community has reason to question the adequacy of safeguards measures. Clearly if the a facility's operation are-is not required for national programs, serious considerations should be given to disposition of HEU and/or decommissioning of the critical facility.

\section{The Generation-IV International Forum}

The Generation-IV International Forum has established a framework for international cooperation in the development of advanced reactor systems ${ }^{4}$ systems $^{5}$. Few, if any, of the proposed systems would require HEU, even for startup cores. The relatively few required mockup assemblies could be handled in a minimum number of internationally accessible, but highly secure facilities. 


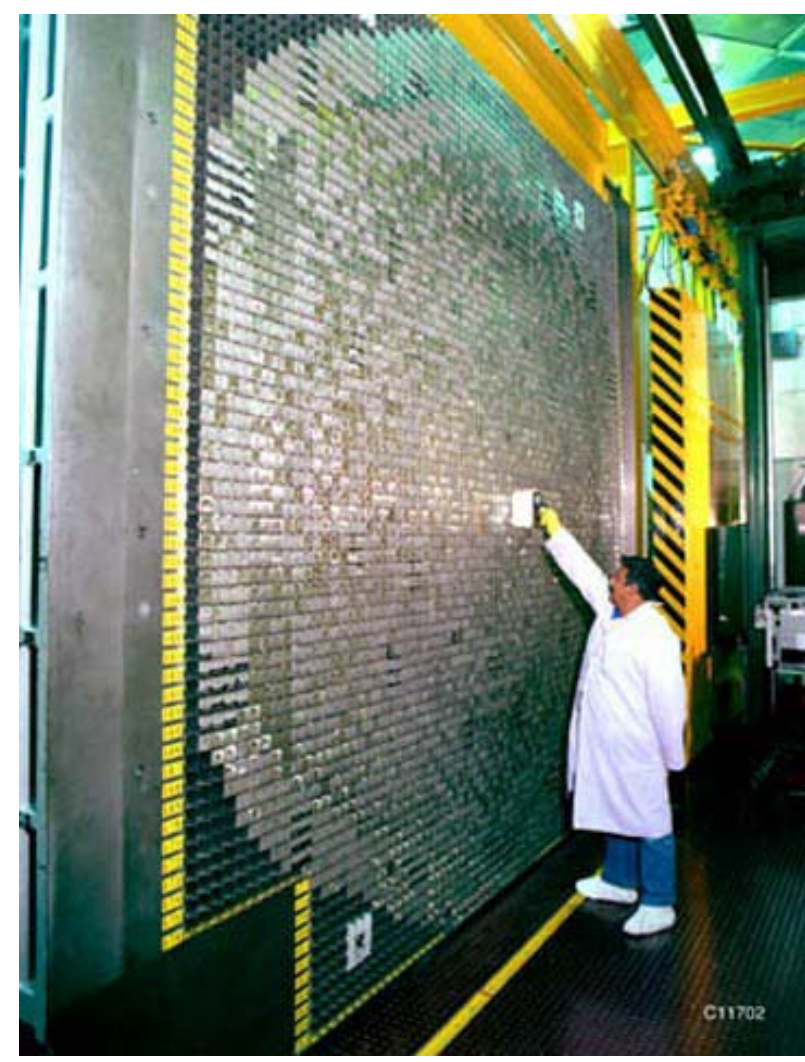

Fig. 2. A large plutonium core in the JUPITER Program

There is a long history of international cooperation and participation in such programs as exemplified by the Japan-US series of JUPITER programs in the 1980's that provided the definitive integral data for large sodium-cooled fast reactors. Some of these experiments have since been analyzed by scientists from other countries. The US had similar cooperative programs with France and the United Kingdom.

\section{Thousands of Documented Experiments}

Global sharing of benchmark criticality data is already a reality. The International Criticality Safety Benchmark Evaluation Project (ICSBEP) ${ }^{5}{ }_{-}^{6}$ - has compiled criticality data for more than 3000 some 3800 configurations and distributed the evaluations to $59-60$ countries. Much of the emphasis of this program has been on preserving data that would have been otherwise lost. It would be a natural extension to make future experiments broadly available to the international community within an appropriate framework such as ICSBEP or the Generation-IV International Forum.

\section{New Tools for Using Existing Experiments}

The key to successfully reducing the required number of critical experiments is the development of a set of analytical tools that can effectively use the accumulated data bases of integral measurements and criticality benchmarks. Such tools have been considered for more than two decades ${ }^{6}$ decades $^{7}$, but have not been developed for systematic application to advanced reactor design. Emerging techniques ${ }^{7}$-techniques ${ }^{8} \mid$ promise to be adaptable to fully utilizing modern computing capabilities toward achieving this end. Further, sensitivity analysis techniques can (and should) be used to design and validate experiments.

The effectiveness of this analytical approach has already been demonstrated by some incomplete work at Argonne National Laboratory ${ }^{8}$ Laboratory ${ }^{9}$. For uranium-fueled experiments, it was shown that the predicted criticality was vastly improved by taking into consideration a whole array of uranium benchmark experiments. Further, there was little improvement by adding a new experiment to the collection, even when that experiment represented a faithful geometric and compositional mockup.

\section{Global Threat Reduction Initiative}

In 2004 President Bush announced a new global threat reduction initiative that was quickly embraced by the IAEA. One of the tenets of this initiative is to "work to convert the cores of civilian research reactors that use high enriched uranium to use low enriched uranium fuel, throughout the world." ${ }^{-}{ }_{1}^{10}$ Although most of the related effort has been directed through the RERTR Program at test reactors that use HEU fuel, the need to secure unirradiated critical facility fuel is equally as great.

Even in the United States, Department of Energy sites are divesting themselves of excess fissile material that is no longer needed by current programs, actions driven primarily by the escalating cost of security requirements. With the implementation of the BLEU Program ${ }^{10}$ Program $^{11}$, the US now has an effective HEU disposition program for taking "off-spec" material and down blending it to $5 \%$ enrichment for acceptable commercial reactor use.

Recognizing the need to effectively manage security costs, the Idaho National Laboratory (INL) has disposed of almost three tons of fissile material, including some $600 \mathrm{~kg}$ of HEU critical experiment fuel plates. The INL plans to dispose an additional eight tons of HEU as resources become available over the next several years. Nevertheless, the Laboratory will continue to maintain a smaller inventory of well-protected HEU for various nuclear energy and national security programs. The latter includes development and testing of systems to detect illicit smuggling of HEU.

\section{Reassertion of the US as Nuclear Technology Leader}

In 1998 the US nuclear research budget sank to zero. By contrast, in 2005 the US Department of Energy created a new lead nuclear energy laboratory-The Idaho National Laboratory. The Bush Administration has strongly urged construction of new nuclear power plants for reasons of energy security and environmental protection. More than two-thirds of all Americans favor the construction of new plants. The nuclear energy research budget is supporting currently installed reactors, Generation IV and the Advanced Fuel Cycle Initiative (AFCI)new power plant construction, 
and the Global Nuclear Energy Partnership. Nonproliferation activities are beginning to focus more on the civilian fuel cycle.

As a part of its nuclear revitalization, the Department of Energy is consideringmay consider whether to upgrade and restart the Zero Power Physics Reactor (ZPPR) which is uniquely suited to supporting large international programs requiring the use of plutonium fuel.

\section{CONCLUSIONS}

The future need for plutonium or HEU fuel to support design and licensing activities will be primarily limited to advanced fast reactors. A very small number of facilities in highly secure locations would be adequate to support global needs if a robust international framework were established. Each of the required elements of such an approach is relatively well developed. Putting these elements together in a comprehensive international program would improve both the quality of design and international security. The GLOBAL series of conferences was created to foster a bold view of our nuclear future. Simultaneously achieving better physics results and global security is a vision worth considering.

\section{ACKNOWLEDGMENTS}

The author thanks Prof. Frank von Hippel for suggesting this topic; Prof. Paul Turinsky for updating him on modern sensitivity analysis techniques, and his colleagues Steven Aumeier, Robert Schaefer and Peter Collins for their consultation and advice.

\section{NOMENCLATURE}

BLEU: Blended Low Enriched Uranium GNEP Global Nuclear Energy Partnership HEU: Highly Enriched Uranium $\left(>20 \%{ }^{235} \mathrm{U}\right)$

IAEA: International Atomic Energy Agency

ICSBEP: International Criticality Safety Benchmark Evaluation Project

INL: Idaho National Laboratory

JUPITER: Japan-US Program of Integral Tests and Experimental Research

LEU: Low Enriched Uranium $\left(<20 \%{ }^{235} \mathrm{U}\right)$

NASA National Aeronautics and Space Administration

RERTR: Reduced Enrichment Research and Test Reactor

ZPPR: Zero Power Physics Reactor

\section{REFERENCES}

1. F. N. VON HIPPEL, "Future Needs for HEU-Fueled Critical Assemblies, to be presented at RERTR-2005, New Orleans (Nov. 6-10, 2005).

2. A. TRAVELLI, "Status and Progress of the RERTR Program in the Year 2004, "," Proceedings of the RERTR 2004 International Meeting on Reduced Enrichment for Research and Test Reactors," IAEA, Vienna- Austria-
(Nov. 7-12, 2004)

3. http://www.gnep.energy.gov/

3.

3.4. "Study Outlines Reactor Designs That May Be Ready for Deployment by Decade's End," Nuclear News 25-33, American Nuclear Society (August 2001)

4.5. Ralph BENNETT, and John KOTEK, "Next Generation | Nuclear Power," Scientific American, Vol. 286, No. 1, 70-79 (January 2002)

5.6. J. Blair BRIGGS et al, "The International Criticality | Safety Benchmark Evaluation Project," Nuclear Science and Engineering 145, 1-10 (2003)

6.7. B. L. BROADHEAD, B. T. REARDEN, C. M. HOPPER, | J. J. WAGSCHAL, and C. V. PARKS, "Sensitivity- and Uncertainty-Based Criticality Safety Validation Techniques," Nucl. Sci. Eng. 146, 340-366 (2004)

7.8. H. ABDEL-KHALIK and P. J. TURINSKY, "Adaptive | Core Simulation: Efficient Sensitivity Analysis," Proceedings of Advances in Nuclear Fuel Management-III Topical Meeting, ANS, Hilton Head, (2003)

\&.9. R. W. SCHAEFER, S. E. AUMEIER, and H. F. | MCFARLANE, "Applicability of ZPR Critical Experiment Data to Criticality Safety," Proceedings of Experts' Meeting on Experimental Needs in Criticality Safety, Albuquerque, NM September (25-26 1995) $\frac{\text { 9.10. http://www.iaea.org/NewsCenter/News/2004/GTR }}{\text { I Initiative.html }}$

10.11. Nuclear Fuel Services, Inc., "Environmental Assessment and Issuance of Finding of No SignificantSsignificant Impact Related to Proposed Amendment to License No. SNM-124 for the Blended Low-Enriched Uranium Preparation Facility," Federal Register Vol. 68, No. 207, (Oct. 27 2003) 